\section{Clinical Neurosurgery Volume 23}

Editor-in-chief E. B. Keener. (Pp. 562; illustrated; £19.95, \$28.50.) Williams and Wilkins: Atlanta, Georgia. 1976.

This volume is probably the most useful contribution which North America makes to the world literature on this subject. The year's delay in reporting the meeting of the Congress of Neurological Surgeons is no longer than that commonly imposed by prestige journals; moreover the resulting papers are fresher than many 'originals' which of ten bear the marks of over-rigid editing. Conference proceedings are often denigrated as belated, unedited accounts of large numbers of brief papers, many of which were not interesting even when read. Clinical Neurosurgery is different because the Congress is different. Each year two or three topics are chosen, and surgeons known to have scmething to say and to be capable communicators are asked to speak. As specialisation grows even within superspecialities, review articles of this kind, which are both up-to-date and authoritative, become more and more important.

Another nice touch is to invite a senior neurosurgeon as guest of honour, for someone to review the guest's contribution and then ask him to sing for his supper. In this volume William Sweet does so harmoniously, with diversity and elegance. As expected he reviews his great experience with painrelieving procedures (cordotomy, facial pain, and peripheral stimulation); but he also deals with craniopharyngioma, and his final paper is advice for the neurosurgeon faced with a malpractice suit. There are three other chapters on aspects of malpractice, a topic which also attracted the attention of a recent German neurosurgical symposium. Perhaps medical affluence brings its problems. It may not have been chance that led to half of the rest of the book being given over to 14 chapters on complications of various neurosurgical procedures. It might be difficult to persuade the preoperative neurosurgical patient who had found this volume to sign permission for surgery; but if his surgeon reads it, then this patient will have a wiser and safer surgeon. The remaining 15 chapters deal with surgical aspects of stroke, including several related to the newly popular revascularisation procedure which microsurgical techniques have made possible. These delicate cperations will fascinate surgeons, but it remains to be seen how much they will benefit patients.

BRYAN JENNETT

Music and the Brain Studies in the Neurology of Music Edited by Macdonald Critchley and R. A. Henson. (Pp. 459; illustrated; £11.50.) William Heinemann: London. 1977.

It is a long time since I have had so much enjoyment from reviewing a book. It is intensely interesting to the professional of neurology and amateur of music though the alternative combination may find some parts rather hardgoing. As there are 24 chapters by different authors it is not practicable to list them and a selection would merely reflect the interests of the reviewer. In a foreword Sir Michael Tippett stresses the composer's task in converting his own psyche to a notation to activate the CNS of others.

Part I has first class accounts of the relevant physiology and psychology of musical experience and practice, from the ears to the hands and vocal apparatus. Some of the literature will be unfamiliar to most neurologists but should be better known, notably on memory and attention in music. The role of the right hemisphere in musical appreciation is well known, but I was not aware of the difference between the musically trained and untrained. Naturally the inheritance of musicality and the significance of early development are discussed, and the emotional aspects of musical experience are not neglected. Part II dealing with musicogenic epilepsy, mental illness in composers, neurological illness in performing musicians, deafness, occupational palsies, and music therapy, is on more familiar territcry. Possibly this accounts for a flagging of interest. Nevertheless, the editors have organised a splendid programme.

J. A. SIMPSON

Monoamine Oxidase and its Inhibition $\frac{\bar{C}}{\bar{C}}$ Ciba Foundation. (Pp. 415; illustrated; $\frac{\omega}{\widehat{D}}$ price not stated.) North-Holland: Amsterdam. 1976.

Publication of symposia proceedings in book form has become increasingly $\stackrel{\circ}{\circ}$ common and sometimes of doubtful $\vec{\overrightarrow{ }}$ value. This criticism has never applied to the Ciba Foundation Symposia. Careful selection of speakers combined with good editing have produced monographs of distinction within which this, on the Monoamine Oxidases, takes place.

Scientific interest in monoamine oxidase (MAO) originally concentrat on its function in liver and at periphere adrenergic nerve endings. This interest was greatly increased when it wgs found, largely by accident, that enzyne inhibition relieved depression. Assers $-\overrightarrow{0}$ ment of their value in depression $\bar{\theta}$ clined partly as a result of a Medical $^{\circ}$ Research Council trial and partly fromo the recognition of dangerous interactions with dietary tyramine. This mono-ō graph may signal a reassessment of that judgement.

The contributions begin with the biochemistry of the enzyme followed by윽 consideration of its regulation, physio- $-\frac{J}{J}$ logical function, and the pharmacological effects of its inhibition. Finally, there are several fascinating papers on the clinical significance of the enzyme:-0 These naturally concentrate on its roleo in depression, and the suggestion is made that a particular type of depression can be identified particularly suited to treatment by MAO inhibitors.

This monograph will be of interest? not only to those in appropriated specialist fields of biochemistry, pharmacology, and physiology but also to alh who find themselves responsible for the treatment of mental and particularly depressive illness.

J. S. GillespiE 